\title{
An Influential Factor upon the Quality of Life in Marine Officers of Maritime Enterprise Based on Culture-Work-Health Model
}

\author{
Jae-hee $\mathrm{Kim}^{1}$ and Soong-nang Jang ${ }^{2}$ \\ ${ }^{1}$ Dept. of Nursing, Kangwon Tourism College, 97, Daehak-gil, Taebaek-si, Gangwon- \\ do, 26034, Rep. of Korea \\ ${ }^{2}$ Redcross College of Nursing, Chung-Ang University, 84 Heukseok-ro, Dongjak-gu, \\ Seoul, 157-657, Republic of Korea \\ 1jh6857@naver.com, ${ }^{2}$ sjang@cau.ac.kr
}

\begin{abstract}
This study confirmed an influential factor upon the quality of life in marine officers of maritime enterprise with the focus on health based on the Culture-Work-Health model. The ship organization culture was indicated to have influence upon a business management system and health. The quality of life in marine officers was illuminated by measuring fatigue, which is subjective emotion of being felt by marine officers. As a result, it was identified that the higher organizational support and self-efficacy lead to a positive impact on health, resulting in having made them recognize fatigue less, and that it leads to a rise in the quality of life in a ship. Accordingly, the health in marine officers who board a ship in healthy status may be a means of life, resulting in bringing forward the necessity of service that has an interest in health in the dimension of welfare service.
\end{abstract}

Keywords: Quality, Life, Marine officers, Culture-Work-Health, Model

\section{Introduction}

Entering the 21st century, there have been many attempts for giving a comprehensively new definition on a human being's happiness and quality of life. Thus, the importance of gauging quality of life or well-being was greatly heightened [1]. Quality of life may be defined as health level in the physical, mental and social aspects depending on an individual's experience, belief, expectation or perception level [2].

The post of seaman, who works in a ship, is on duty in special environment dubbed a ship with being segregated from home and society for a certain period. A seaman is exposed to the diversely and rapidly environmental changes such as high noise given the ship operation, coldness \& heat wave, high temperature, and air humidity distinction, thereby having many physiological changes caused by the three-shift work along with working in a ship for over 6 months, resulting in suffering difficulty in maintaining homeostasis of the body [3]. This job environment is becoming a cause for human error such as triggering safety accident or marine accident on the sea as well as giving bad influence to seamen's health because seamen's stress and fatigue are accumulated [4][5]. If the ship organization understands a point that the stress [6] of coming from the closed and special working environment is in the environment accompanied by many restrictions to activity, the ship organization should be the one that gives priority to seamen's qualitative satisfaction [7].

Article history:

Received (July 30, 2016), Review Result (September 02, 2016), Accepted (October 03, 2016) 
Marine officers board a ship with the cycle from 6 months to 8 months based on a method of making an employment contract with various maritime enterprises through a ship management company and then come to form a work team inside a ship with relieving a shift. [8]. This may have negative influence upon forming the stable organizational culture. Also, a job delivery system in the ship organization is taking a method that allows masters and chief engineer to issue an order with hierarchial structure. Hence, the level of influencing member's duty and attitude according to a communication method in masters and chief engineer can be said to be bigger compared to other organizations [7]. Also, the organizational culture in ship organization in which even the individual life needs to be parallelled with accepting a marine risk in the restricted space with being secluded from society for a certain period comes to have a greater influence upon members' self-efficacy compared to other organizations [9]. An environmental factor of influencing self-efficacy includes job complexity, risk bearing, physical condition, and task. Above all, a relationship among members, which is an environmental element of determining organizational culture, will be important [7]. A drop in self-efficacy caused by seamen's stress comes to have effect on organizational commitment and may lead to a fall in productivity of organization [9]. This can have influence upon organizational health and individual health depending on organizational culture in a ship. Accordingly, a consideration is needed on an influential factor upon members' attitude and behavior in ship organization. In the meantime, a research on a method of securing [10] and a research on a reduction in turnover rate through development in public welfare system [11] have been brought up in this aspect. It is becoming a partially substantial solution, but is remaining in the approach of the quantitative and institutional aspect.

Hence, it is enough to be valuable to attempt a research based on theoretical background in order to systematize a method available for generally confirming the organizational culture in the ship organization, the self-efficacy, and even the life satisfaction, which affect marine officers' job satisfaction and job commitment. The social and psychological stress, which is exposed in the working environment, not only aggravates intensifies fatigue but also increases a risk of new mental and physical disorders caused by it. Thus, the intervention in the preventive dimension will be an important nursing matter.

Hereupon, this study aims to identify the influence of self-efficacy according to this upon marine officers' individual and organizational health and further quality of life based on the organizational culture to which the marine officers belong, by applying Culture-Work-Health model [12] by Peterson and Wilson. Through this, it will be a concept available for suggesting a theoretical basis in understanding marine officers' quality of life in a ship.

\section{Purpose of research}

It is what closely examines which influence the culture in maritime industry has upon marine officers' self-efficacy and quality of life on the basis of the Culture-Work-Health model. Specific objectives are as follows.

First, based on a model of this study, it extracts measurement item and scale for the ship organizational culture, organizational support, and marine officers' self-efficacy, perceived fatigue \& quality of life in maritime industry through a previous research.

Second, through an empirical analysis, it analyzes which mediating effect the organizational support, self-efficacy and perceived fatigue have in the influence of organizational culture in maritime industry upon the business management system and the quality of life. 
Finally, this study aims to propose implications by grasping a factor of affecting marine officers' health in the organizational dimension.

\section{Research model}

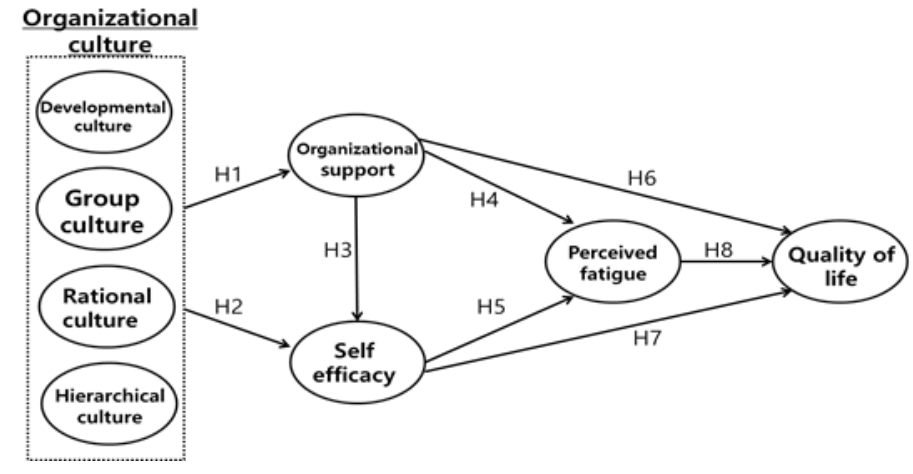

Figure 1. Research model

\subsection{A conceptual frame of research}

This study implemented the following conceptual frame based on the Culture-Work-Health model (CWHM) by Peterson and Wilson.

It was formed as follows on the assumption as saying that the marine officers' quality of life based on CWHM is determined by organizational culture, business management system structure, behavior and health. An antecedent of the business management system is organizational culture. An outcome variable of the business management system includes the perceived fatigue and the quality of life. Accordingly, the construct necessary for a model of this study was made as what the organizational culture, organizational support, self-efficacy, and perceived fatigue have influence upon marine officers' quality of life. It was supposed that the organizational support and self-efficacy have an effect on the perceived fatigue and that the organizational culture has an impact on the quality of life.

\subsection{Research subjects and analytical method}

This study passed through the approval of the research ethics committee of a university to which this researcher belongs in order to protect the questionnaire subjects targeting shipping companies of belonging to maritime industry in the Republic of Korea (IRB No: 1041078201605-HR-095-01). Out of totally 300 copies, 280 copies were collected and analyzed targeting marine officers who have the boarding experience for more than 6 months as those who agreed to this study. In terms of a statistical analysis, the Cronbach's a coefficient and the confirmatory factor analysis were conducted for the reliability in a variable through SPSS/PC 20.0. The path analysis was carried out by using AMOS ver. 21.0.

\subsection{Reliability in measurement variable and tool}

All the measurement items, which were used in this study, were gauged with a 5-point Likert scale from " 1 point= Not so at all." to "5 points= So yes." The reliability in a research stood at organizational culture Cronbach's $\alpha=$. 860, organizational support Cronbach's $\alpha=$. 
942, self-efficacy Cronbach's $\alpha=.914$, Perceived fatigue Cronbach's $\alpha=.835$, quality of life Cronbach's $\alpha=893$.

\section{Findings}

As a result of carrying out an analysis according to the maximum likelihood method using AMOS for verifying the overall model, it is the optimal model that has $\chi^{2}=10.912$ (d.f.=9), $\mathrm{p}<.001, \chi^{2} /$ d.f. $=1.364$, GFI=.990, AGFI=.957, CFI=.998, RMR=.010, NFI=.994, IFI=.998, $\mathrm{TLI}=.994$ in the goodness of fit as [Figure 1]. R2 value was indicated that the organizational support is explained $.713(71.3 \%)$ by components of the organizational culture. The selfefficacy was analyzed to be explained $.479(47.9 \%)$ by components of the organizational culture. In addition, fatigue was shown to be explained $.530(53.0 \%)$ by organizational support and self-efficacy. Finally, the quality of life is analyzed to be explained .368 (36.8\%) by organizational support, self-efficacy, and fatigue. Thus, the overall Fit and the explanation power in the research model are judged to be appropriate.

Organizational culture was indicated to have influence upon organizational support and self-efficacy. Organizational support affected self-efficacy. Also, it can be known that the organizational support and the self-efficacy had a negative effect on fatigue and that the selfefficacy had a positive effect on quality of life.

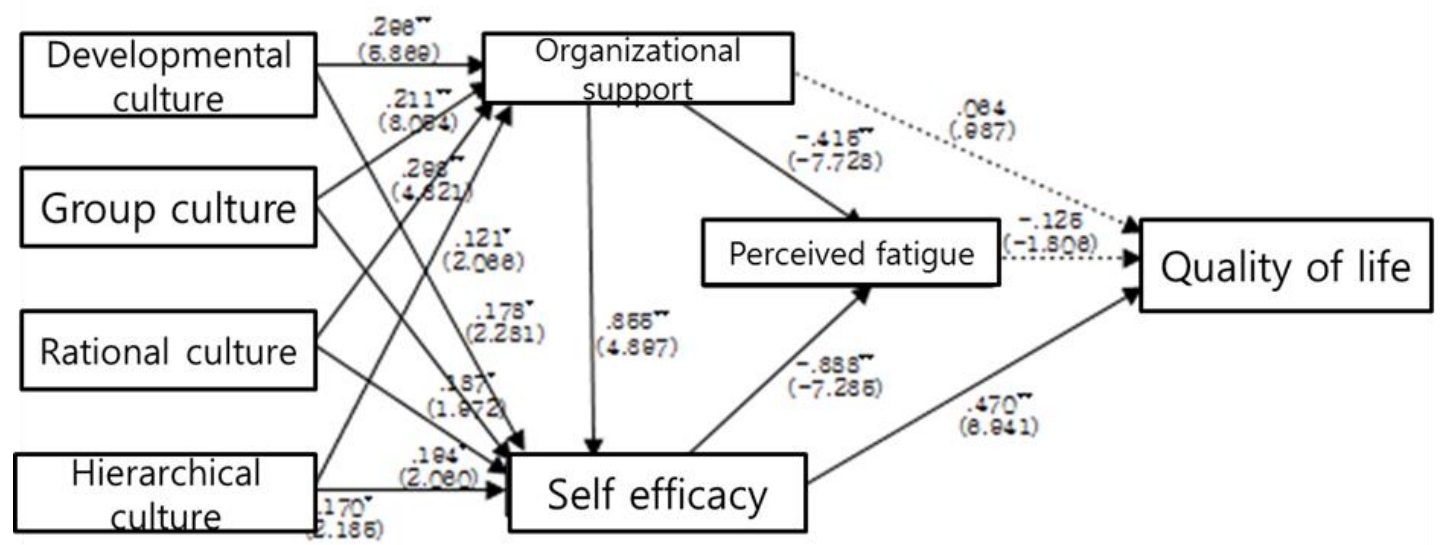

$\chi^{2}=10.912\left(d_{.} .=9\right), p<.001, \chi^{2} / d . f .=1.364, G F I=.990, A G F I=.957, C F I=.998, R M R=.010, N F I=.994, I F I=.998, T L I=.994$ $* p<.05, * * p<.01$

Figure 2. Findings

\section{Conclusion and implication}

This study aimed to confirm an influential factor upon the quality of life through a path analysis targeting marine officers in the maritime industry based on the Culture-Work Health model.

First, it confirmed an influential factor that their culture has upon the quality of life in a ship while having an environmental element unavailable for social interchange. A research will need to be implemented on a plan available for positively intensifying the business management system of making it positive in marine officers' ship culture in maritime industry.

Second, the business management system in maritime industry had negative (-) influence upon fatigue perceived by marine officers and showed the explanation power of $36.8 \%$. This 
may be expected that the managers of operating a ship will need to have a great interest in marine officers' health welfare by grasping the dimensions available for heightening efficiency of a ship with high human reliance by which the organizational support and encouragement for marine officers' job satisfaction have positive influence upon marine officers' health.

Third, the business management system in maritime industry was shown to have effect on marine officers' quality of life. The welfare service or the corporate support level felt by marine officers had positive influence upon marine officers' self-efficacy and further had impact on health. This affected the quality of life.

This outcome may be analyzed that the marine officers can increase self-confidence and achievement based on belief and trust in organization by initiating the atmosphere of maritime industry that causes an interest in own work and allows self-confidence and achievement to be felt according to the culture in a ship to which marine officers belong. Also, it leads to being satisfied with job and to showing positive response to organization, thereby solving fatigue caused by own task with the positive direction along with a rise in selfefficacy, resulting in being possibly expected to be satisfied with own work and to show positive response for development in oneself and maritime enterprise. Hence, it will be a method of the successful personnel management for the management in maritime enterprise to establish and manage the culture system in which the business cooperation is well made with marine officers from masters who manage marine officers. An individual in marine officers is satisfied with job and has high satisfaction at maritime enterprise felt by oneself, thereby being likely able to manage the healthy quality of life in a ship even inside the space that is disconnected from society. Seeing from the long-term perspective through this, it is expected to be presumably able to contribute to the development in maritime industry.

Fourth, the marine officers' perceived fatigue and organizational support were indicated to have no influence upon the quality of life. This suggests that the marine officers of taking ship are available for boarding only in the healthy status, thus the health will be a means of life in marine officers. This hints that a sight of looking at health in a social stratum should be varied and that the diversity in society needs to be recognized in a concept of inequality . This is a new concept of seeing health. Health is a means. Hence, a plan will need to be arranged that can raise function available for making social life rather than wealth for health.

This study has the following limitations despite of having presented theoretical and practical implications based on the empirical analysis by progressing a research targeting marine officers among the employees in maritime industry of Busan area in South Korea. Thereupon, a future research direction is aimed to be proposed. First, the research subjects are limited only to marine officers who belong to maritime industry in one area, thereby having limitation in representative-ness enough to be applied to the whole marine officers. Hence, a future research should be carried out a comparative research by being applied to marine officers by many countries as well as South Korea. Second, it is varied the organizational culture by ship and the organizational support by maritime enterprise, thereby being likely differentiated a perception level of marine officers who recognize this. Thus, a future research will need to be conducted a research of comparing a difference by maritime enterprise. Third, a comprehensive research will need to be developed that verified the influence of a model by making it different in a scale based on the Culture-Work Health model. 


\section{References}

[1] M. Nicolaisen, S. Müller, H. R. Patel, and T. A. Hanssen, "Quality of life and satisfaction with information after radical prostatectomy, radical external beam radiotherapy and postoperative radiotherapy: a long term follow-up study," Journal of clinical Nursing, vol.23, pp.3403-3414, (2014) DOI:10.1111/jocn.12586

[2] M. A. Testa and D. C. Simonson, “Assessment of quality-of-life outcomes," New England journal of medicine, vol.334, pp.835-840, (1996)

[3] M. Jeżewska, M. Grubman-Nowak, and J. Moryś, "Quality of life at sea in Polish seafarer's evaluation," International maritime health, vol.66, pp.247, (2015) DOI:10.5603/IMH.2015.0046

[4] P. H. Allen and A. P. Smith, "New film on seafarers' fatigue," International maritime health, vol.62, pp.155, (2011)

[5] T. Carter, "Seafarer medicals: population health or private gain?" International maritime health, vol.67, pp.1, (2016) DOI:10.5603/IMH.2016.0001

[6] V. Malinauskiene, "Sense of coherence and mental health among seafarers in relation to physical activity," Occupational and environmental medicine, vol.71, Supplement 1, pp.A109, (2014) DOI:10.1136/oemed2016-103951.546

[7] J.-Y. Son, Y.-J. Shin, and J.-K. Lee, "The impact of leader's communication style on the conflict and job attitude in ship organization," Journal of Korea Port Economic Association, vol.30, pp.59-87, (2014)

[8] J.-T. Kim, H.-H. Cho, and Y.-J. Shin, "A study on the effect of swift trust on the cohesiveness and organizational effectiveness of ship organization,” Journal of Korean Navigation and Port Research, vol.37, pp.429-438, (2013)

[9] T.-J. CHOI, I.-H. Back, H.-H. Won, and J.-U. Park, "The effect of Self-Efficacy of marine officer on job satisfaction and self-development," Journal of Fisheries and Marine Sciences Education, vol.27, no.4, pp.1136-1146, (2015) DOI: 10.13000/JFMSE.2015.27.4.1136

[10] Y.-S. Chung, Y.-J. Shin, and H.-S. Pai, "The Effect of foreign crew's cultural homogeneity on the Selfefficacy and organizational commitment," Journal of Navigation and Port Research, vol.30, pp.643-648, (2006) DOI:10.13140/2.1.4036.6080

[11] M. Peterson and J. F. Wilson, "The Culture-Work-Health model and work stress," American journal of health behavior, vol.26, pp.16, (2002) DOI:10.5993/AJHB.26.1.2

[12] J. H. Lee, "The regional health inequity, and individual and neighborhood level health determinants," Health and Social Welfare Review, vol.36, pp.345-384, (2016)

\section{Authors}
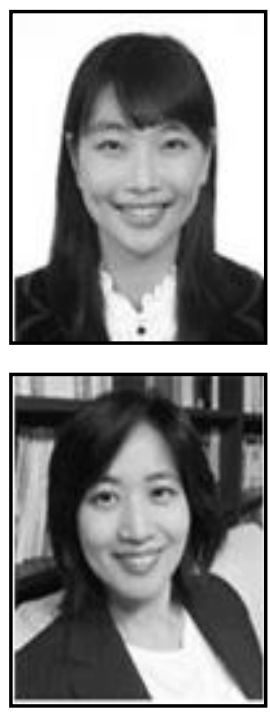

Jae-hee Kim

Adult Health Nursing, Society for Equity in Health

\section{Soong-nang Jang}

Community Health Nursing, Senior Public Health, Society for Equity in Health 